\title{
A curriculum map of colorectal surgery: an assessment of training expectations and the reality
}

\author{
C May \\ From International Conference for Healthcare and Medical Students 2011 \\ Dublin, Ireland. 4-5 November 2011
}

\section{Introduction}

There are national guidelines for the curriculum of each surgical specialty, encompassing set competencies and attitudes expected of trainees at each level. Conventionally assessment is based on the trainee and not delivery of the curriculum. By performing the curriculum map it reviews the trainees' ability and also the quality and breadth of delivery by seniors.

\section{Methods}

The initial phase involved comparing trainees expected skill level against their subjective competency in a number of areas. Data was then collected, covering a twelve month period, tallying the number of elective procedures carried out. By comparing this data against expected trainee progression it was possible to assess if there was adequate exposure for such a level to be achieved.

\section{Results}

The subjective data collected from the trainees themselves suggested they were comfortably achieving the set competencies within their training band. Despite collecting data across four consultants elective theatre lists there were a number of procedures, detailed within the set curriculum, that had not been performed during the twelve month period. Alongside this there were a number of procedures that were performed in such low numbers that trainees would not receive adequate exposure and training opportunities.

\section{Conclusions}

Conducting the curriculum map highlighted key areas where trainees might be missing out on valuable learning

University of Manchester, UK opportunities which potentially may not have been picked up on until formal assessment. The methods used for conducting a curriculum map are not without flaws though. Using data that requires subjective assessment of skills can lead to false beliefs about efficacy of curriculum delivery. Ultimately it is therefore essential that formal trainee assessments are running concurrently with curriculum maps at each site.

Published: 9 July 2012

doi:10.1186/1753-6561-6-S4-O4

Cite this article as: May: A curriculum map of colorectal surgery:

an assessment of training expectations and the reality. BMC Proceedings 2012 6(Suppl 4):O4.
Submit your next manuscript to BioMed Central and take full advantage of:

- Convenient online submission

- Thorough peer review

- No space constraints or color figure charges

- Immediate publication on acceptance

- Inclusion in PubMed, CAS, Scopus and Google Scholar

- Research which is freely available for redistribution
() Biomed Central (c) 2012 May; licensee BioMed Central Ltd. This is an Open Access article distributed under the terms of the Creative Commons Attribution License (http://creativecommons.org/licenses/by/2.0), which permits unrestricted use, distribution, and reproduction in any medium, provided the original work is properly cited. 